\title{
A Research on using Geo-polymer Mortar as Repair Mortar
}

\author{
Akhil Thakial* and Gurinder Kaur \\ Department Civil Engineering, Chandigarh University, Mohali - 140413, Punjab, India; \\ akhilthakial@gmail.com,gurinder.civil@cumail.com
}

\begin{abstract}
Objectives: To study the formation of geopolymer repair mortar; Secondly, results of repair mortar are to be evaluated in comparison with commercial repair mortar. Methods/Statistical Analysis: The methodology adopted in this research is about geo-polymer repair mortar. For this method, geo-polymer mortar is made to repair cracks and to increase the compressive strength of structure. Polymerization technique is employed for making mortar. With this research the waste material like fly ash is added to mortar with lesser cement content that holds it up economic. Compressive test and split tensile test were performed. Findings: The research arrives at the conclusion of the reduction in pollution with good compressive strength. The addition of fly ash in cement mortar makes it lighter and helps in gaining good strength. Due to low cement content and higher the fly ash content, it is compared with commercial repair mortar resulting better results. The study evaluates the difference in cost and the time taken. Therefore, when the addition of fly ash increases up to some percent the cost of the material decreases by $20-30 \%$ after comparing with commercial repair mortar due to which it is easier and more helpful for Indian construction companies to maintain budget easily. Application/Improvements: Geopolymer mortar servers many applications which include: better scheduling of cost, recognition of time, cost estimation during whole project.
\end{abstract}

Keywords: Fly Ash, Geo-polymer Mortar, Repair Mortar

\section{Introduction}

Mortar is serviceable glue that is utilized to tie building pieces, for example, blocks, stones and cement together and independently fill and seal the sporadic holes between all. This glue is acquired by adding water to a blend of all these fine totals, for example, sand and other restricting materials. The pyramids of these have been worked with gypsum lime, earth gypsum and furthermore lime mortar. Bond mortar acquires quality when it cures, bringing about unbending total structure. Along these lines, repair mortar is required to be by some methods that are not stronger than building pieces and, in this way, the concil- iatory component in the brick work, on the grounds that the concrete mortar is simpler to make and more affordable to repair as in examination with building squares. It gives some power or union between the basic unit. It goes about as a medium for appropriating every one of the powers all through the structure similarly. Mortars are by and large produced using a blend of materials like sand, a fastener and water. Additionally, mortar is a blend of sand and bonds that is frequently and normal and used to construct block or piece dividers. Mortar has been utilized for a protracted time as methods for following blocks or solid squares. The most well-known and effectively accessible fastener since the mid twentieth century is the Portland

${ }^{*}$ Author for correspondence 
concrete however the old cover that lime mortar is as yet utilized as a part of some new development work. Bond mortar influences a phenomenal medium for making a smooth surface to dividers to and are produced using blocks.

The quality of mortar is low contrasted and cement. It is more functional than concrete. Gypsum and lime as mortar of Paris are as of now utilized especially in repair and repointing of the structures and structures since it's critical that the repair materials are like unique materials. The sort and the proportion of this repair mortar is likewise controlled by investigation of mortar process. Geopolymer mortar is extremely potential material for an assistant application as a choice of standard Portland bond concrete. Be that as it may, low calcium fly blazing stays based geopolymer concrete achieved splendid quality and mechanical properties, when cured in high temperature. Expect that by taking out bond and utilizing more outcome materials. Advantage of using fly ash with geopolymer mortar helps in less bleeding, increased workability, setting time should be increased. The main and important purpose of mortar is that it will bind along two individual masonry units. It additionally provides good and proper protection against air and water penetration between the joints. The main issue of use of fly ash as a replacement material for cement is the need of heat curing regime to achieve structural integrity and lower standard deviation which means improved stability of AASF mortar specimens ${ }^{1}$.

The durability of geopolymer mortar and concrete is highlighted in terms of their deterioration in various aggressive environments. Research and development works were carried out on heat and ambient cured geopolymers at CSIR-CBRI (Central Building Research Institute) for 4 months 2 . Mortar mixes with ingredients which gives more strength that is cement which are good in bond making and also provides very fine workability. Geopolymers from laterite, laterite from to go (Africa) was used to prepare geopolymers using both phosphoric acid and alkaline sodium silicate solution 3 . The geopolymer mortar which has high cement content provide additional strength then the opposite all we are able to say that may be stronger however provides less Bond. In geopolymer mortar the gain in the strength will be more in early time. Good bond between mortar and masonry contributes a good masonry wall which is weather resistant. Also, the durability of geopolymer mortar and concrete is highlighted in terms of their deterioration in various aggressive environments. Research and development works were carried out on heat and ambient cured geopolymers at CSIR-CBRI (Central Building Research Institute) for 4 months ${ }^{4}$. Compressive strength is in range of 0.9-4.35 MPa, which is suitable for using as bricks, fire resistant panels and so on. Microstructure analysis shows fast reaction between $\mathrm{Al}$ powder and alkali activator. Aerating of geopolymers causes damages in stoichiometry of alkali activator and incomplete geopolymerization of fly ash $\underline{5}$.

The balance in mortar in its strength and Bond is extremely vital or we are able to say is needed. With this mortar shows each smart unstable performance yet because it is weather resistant. web site review of cement mortar is usually notconcern for good designers. New mortar material more reliable and Powerful strength development and have much higher rate of gaining strength as we have seen using various form of lime. We are looking for mortar should be workable, well-proportioned which mixes well to ensure that having good installation and have long term performance. The lime which is previously used inverter had very much acceptable working properties but problem is in the strength gaining vigorously is low, especially in cold climatic conditions. From $8-22 \%$ off the wall space is taken and coated by mortar (depending upon the scale of mortar). Therefore, the original colour of mortar appears significantly after it is used in wall. In other words, the colour appears when the mortar is used or dried up in the wall. Generally natural colour of mortar is grey, which is most common. The brick easily sets of with mortar and is economical. Water demand increases with increase of LKD. Thus, further results show that the final and initial setting time is accelerated due to addition of LKD. This reduces the density of mortar- Joining of Mortars with the brick has an impact on water resistance, this shows the joint profile of cement mortar. This increase shows better durability of concrete with geopolymer coating due to reduced 
decomposition rate. The result shows that applying the alkaline solution and geopolymer coating thus increases the durability of pozzolan concrete ${ }^{\mathrm{z}}$.

Cement mortar or masonry cement, produced at factory is neither too strong nor too weak in strength. The Portland cement which is produced in factory is blended form, also limestone and Fine silica and some air entraining admixtures are used in masonry. However, site made mortar are very common in today due to increased emphasis on the daily need for instant mixing, accurate and for less time consumption. This means that factory produced cement are taking on increasing share in the market which leads to offsite mortar. Therefore, in today It is rare to find mixing on site. Factory made mortar are of following types:

Dry ready mortar

Wet ready mortar

Line sand mortar

\subsection{Dry Ready Mortar}

This type of mortar is in dried form which is mixed with sand, sometimes with the extra addition of admixtures. These bags are stored on site in bulk silos. The silos are incorporate their own mixtures. This allows the mixing of Mortars at any time in any desired or required amount.

\subsection{Wet Ready Mortar}

Wet ready mortar is also a mixture of cement and sand (also referred to fine aggregate). Though sometimes it contains a cement retarder in addition with lime. Water is added in the factory so that the final mix remains workable for specific time. Generally, it remains workable for 48 hours, the mortar is normally delivered from one site to another in bulk quantity, using alligator or specified vehicles which are capable of moving the Mortars from factory to the site.

\subsection{Lime Sand Mortar}

This type of mortar is pre-batched sand and lime, during this form of mortar it contains some admixtures that also requires cement and water addition in it on site. The material is commonly delivered with the help of skips or Jumbo bags, tippers, trucks etc.

The wide use of Mortars or cement mortar throughout the times makes the development and the infrastructure good which tends to be very useful on building construction. In short, the mortar aims to provide very nice building background till date. The lime mortar gets harder easily and thus gain better strength with respect to evaporation of water and absorption of carbon dioxide which is present in the atmosphere. This results that lime mortar gradually converts into calcium carbonate and with this process as we say the mechanism process takes very long time to produce better strength. The mortar or lime mortar has different compounds which shows cementitious properties that helps in the gaining of prolonged strength of the mortar. There are many examples which provides evidence of proper durability of cement masonry materials and some historic lime mortar.

Here is some glossary of terms which are defined in some categories like building limes, carbonation, false set, gypsum, hydrated lime, air limes etc. Material comparison any physical and chemical form under which magnesium oxide or calcium or calcium hydroxide can appear. Geopolymer mortar is produced by some aluminosilicate source material combining some compounds which are pozzolanic with highly alkaline solutions. Fly Ash, after burning coal and thus it is available worldwide or we are able to say flyash is a composite Binder made from coal burning operation is a cheap supplementary cementing material which is common throughout the world and is very economic. Largely huge quality of fly ash is produced daily in the factories but only very few amounts of this Binder is used and has very good applications as it is waste and with the help of soluble glass or hydrated oxide ash shows excellent building material properties while not soluble glass and hydrated oxide it is just a waste and no cementitious properties will occur. The shrinkage of geopolymer concrete up to the age of 180 days was found comparable to that of (OPC) ordinary Portland cement concrete of similar compressive strength. Thus, shrinkage of geopolymer concrete measured at $28^{\text {th }}$ day was higher than the design shrinkage ${ }^{8}$. 
The 28th day strength increased from $26 \mathrm{MPa}$ to 56 MPa when the binder content is increased from $450 \mathrm{~kg} /$ $\mathrm{m}^{3}$ to $730 \mathrm{~kg} / \mathrm{m}^{3}$. Best results are calculated when binder content was in range of 550 to $650 \mathrm{~kg} / \mathrm{m}^{3}$. Thus, fly ash geopolymers blended with small percentages of GGBFS, OPC or $\mathrm{CH}$ that can be a suitable binder'. It's terribly low shrinkage and creep then our conventional concrete. Although Geopolymer mortar is better than conventional mortar concrete and shows better performance in fire, due to their good ceramic properties and early strength gaining properties. The geopolymer which is made with fly ash is usually very economic, investigations done by the engineers shows that geopolymer has potential to stand up to $500^{\circ} \mathrm{C}$. This also includes investigation over geopolymer composite with concrete and mortar. Generally, mortar and concrete were tested for his or her compressive strength at the seven days, 14 days, 28 days etc. At each level of testing proper maintenance of temperature is done in the interval of every one hour. The characteristics of GPC mix are identified. The researchers consider the water to geopolymer solid and alkaline liquid to fly ash ratios as direct measure of strength and workability. Most importantly, relationships have been established between these important parameters in order to achieve a certain level of strength together with desired workability ${ }^{10}$. Geopolymer concrete within which ash is associate degree additive has low metal ash includes typically crystalline, haematite and quartz. The loss of ignition of ash geopolymer mortar is set by $\mathrm{x}$-ray light. Alkaline activators play very important role in the investigation which consists of alkaline silicate and hydroxide solution. Locally Hydroxide solution is prepared or required to some molarity victimisation hydrated oxide flakes up to ninety-five to ninety-eight purity and $\mathrm{H}_{2} \mathrm{O}$. offered coarse aggregates and fine aggregates which have saturated surface conditions when used as coarse aggregates usually consists of crushed basalt from local manufacturers and so fine aggregates is collected from river.

Different coarse aggregates are used manually with crushed granite aggregate and different form of fine aggregates was sand. The aggregates have such size as per the investigation and therefore the demand. For, standard
Portland cement composites normal brand is used confirming to desired or required grade is used. the blending of mortar/concrete is finished in an exceedingly mixer that is on the market within the concrete laboratory. ash and therefore the mixture work along for regarding couple of minutes. Geopolymer mortar doesn't need any activity within the case of mortar. chemical change of soluble glass and hydrated oxide which was mixed with distilled water is done complete and mortars have very different properties based on the chemical and physical properties of geo mortar is compared as a repair material. In Early Times the made by the masons have very good strength and stability till now, this is because of good quality mortar material used in them. Different moulds for both mortar and concrete are used so that proper investigation and testing can be done. All specimens were cured undisturbed for a minimum of three days at some totally different close conditions. once the specimen was aloof from the moulds, the concrete cubes which needs activity were placed in storage tank for a specified time interval. Geopolymer concrete has very useful properties in which alkaline liquid is mixed. Geopolymer is also termed as alkali activated material that define molecules linked with covalent bonds. Polymerization of inorganic specimen like ash, slag etcis accomplished with the use of this alkaline solution. The energy has high potential so that it is often used as renewable energy. Geopolymer is environment friendly inorganic material, derived from alkaline solution in which activated Alumina silicate material is present such as metakaolin, fly ash and slag. Therefore, it also shows mechanical properties just like ordinary Portland cement. Most of the researchers have observed complex properties. Some have reported a superior durability mortar and concrete containing activated-alkali binder ( $\mathrm{AAB}$ ) with various activators. Effective reuse of pozzolanic materials can have many advantages such as reduction of cement consumption, construction cost and $\mathrm{CO}_{2}$ emission. At last the disposal problem can be minimized by their effective consumption ${ }^{11}$.

Standard Portland cement is wide used as a binding material however geopolymer mortar is currently used as a replacement and as a repair material from decades. 
Shortage of natural resources for construction work in many different countries with different climatic conditions is faced and due to fly ash or geopolymer mortar can help find this solution. The mechanical properties in which chemical activator or alkali activated solution is a necessity which is used to increase the hydrolysis of aluminosilicate particles present in raw material. The presence of chemical activators such as hydrated oxide and soluble glassin the combo style of geopolymer full forms vital impact on the properties of geopolymer mortar.

\section{Research Methods and Procedures}

The event of geopolymer mortar combine is finished with main concentrate on its compressive strength. The geopolymer mortar is to be used as a repair mortar for both strength and economy. Firstly, the commercial mortar is compared with repair mortar which is made in the laboratory. The most important component that should be used for making geopolymer mortar is the material. Thus, for further Research and methods for the making of geopolymer mortar we should have certain materials.

\subsection{Mechanism of Geopolymer Mortar}

Geopolymerization is a very complex process that is attained by associate degree exothermic production, the various stages of geopolymerization are: -

- Destruction to activity

- Activity to condensation

- Condensation to crystallization

Typically, the two main stages that are needed or administrated to create geopolymer mortar: the primary date that features aluminosilicate dissolution and therefore the formation of polymers, and the second stage that includes the growth of polymer particles from the initial stage to final stage. Dissolution stage starts when alumi- nosilicate from raw material get in contact with the basic resolution, to supply the salt and metal species. several variables like $\mathrm{K}$ and metal that are basic in nature forms concentration, rate, time combining.

The purpose of this analysis is to supply new artefact (geopolymer) that may be utilized in repair functions and might bind elements of typical concrete and mortar (sand and gravel)in comparison with Portland cement depending upon local materials with addition of other cementitious material like fly ash.

\section{Materials}

The experimental work that has to be done to manufacture geopolymer mortar by victimisation ash. Several trial mixes were created within the experiment to seek outthe optimum proportions and results, these proportions effects on this kind of mortar are: -

- Fly Ash

- Ratio of fly ash to alkaline solution, $\mathrm{NaOH}$ and $\mathrm{Na}_{2} \mathrm{SiO}_{3}$

- Extra water content

- Ratio of $\mathrm{NaOH}$ to $\mathrm{Na}_{2} \mathrm{SiO}_{3}$

- Ratio of fine to total aggregate content

- Quantity of commercial mortar

- Distilled water

\subsection{Materials and their Properties}

Fine aggregate: Traditional sand was used as fine aggregate during this work with the scale of $4.75 \mathrm{~mm}$ and has grading limit zone 5 . Sieve analysis process is done to remove gravel from sand. Results have found that fine mixture grading and size is acceptable. The physical and chemical properties ofsand is also analysed. 
Mixing water: The normal tap water which is used for daily purposes, combining and for activity throughout the work that's provided by water supply system.

Fly ash: Fly ash(FA) may be a by-product of pulverized coal and is extremely fine and glassy. It is a waste product and exhibit cementitious properties in it. It has a significant amount of silicon dioxide and also contain calcium oxide, magnesium, potassium, sodium, titanium and sulphur which are present in very less amount. There are two main sorts of fly ash named as class $\mathrm{C}$ and class F. Class $\mathrm{C}$ are high metal fly ashes with carbon content but two and sophistication $\mathrm{F}$ are low metal fly ashes with carbon content but five-hitter. category $\mathrm{F}$ ash is employed during this experiment.

\section{Preparation of Alkaline Solution for Geopolymer Mortar}

The basic resolution of geopolymer mortar constitutes soluble glass and hydrated oxide. thanks to high purity of hydrated oxide i.e. $98 \%$ and might be dissolved in $\mathrm{H}_{2} \mathrm{O}$ to supply associate degree basic resolution with acceptable concentration. $\mathrm{NaOH}$ concentration is fastened to eight molar, mass of hydrated oxide solid during this resolution might vary relying upon the concentration of the answer. The soluble glass resolution is commonly present and available in various types. The proportion by mass of both these components in $\mathrm{Kg} / \mathrm{m}^{3}$ were, $\mathrm{NaOH}$ 480.64 and $\mathrm{Na}_{2} \mathrm{SiO}_{3}-961.3$. Once getting ready hydrated oxide $(\mathrm{NaOH})$ resolution. it had been supplemental to soluble glass $\left(\mathrm{Na}_{2} \mathrm{SiO}_{3}\right)$ resolution. The basic resolution is that the combination of each hydrated oxide resolution and soluble glass resolution, and before victimisation the basic solution should be ready by combining each solution along for a minimum of twenty-four hours earlier. The water content supplemental should be additional once utilized in geopolymer mortar with totally different contents to boost workability. Finally, the mixing of extra water content with the alkaline solution should be done but not but two minutes. Several trial combines of geopolymer mortar were created to pick the suitable mix, additionally reckoning on the dynamical of elements of geopolymer mortar combine for reaching and to attaining the simplest combine that provides the best compressive strength. Fine mixture content is same for all the mixes but the quantity of cement or we can say the percentage of cement vary because the quantity of ash will increase within the combine the mix.

Curing: The normal concrete specimens what placed in water tank after demoulding to the age of take a look at. The temperature throughout the activity was unbroken in the range of 25 to $30^{\circ} \mathrm{C}$.

\section{Mixing Procedure of Geopolymer Mortar}

Silica and aluminium in fly ashreact with the basic resolution $\left(\mathrm{NaOH}\right.$ and $\mathrm{Na}_{2} \mathrm{SiO}_{3}$ ) to create a fine paste of geopolymer that creates bond with fine mixture and with

Table 1. Mix proportions of materials used in geopolymer mortar

\begin{tabular}{|c|c|c|c|c|c|}
\hline \multicolumn{7}{|c|}{ Mix proportions in Kg/m } \\
\hline Percentage & F.A & OPC & Sand & NAOH & NA $_{2}$ SiO $_{3}$ \\
\hline $0 \%$ & 2403.23 & - & 2403.23 & 480.64 & 961.3 \\
\hline $10 \%$ & 2160.01 & 240 & 2400.01 & 480.64 & 961.3 \\
\hline $15 \%$ & 2040 & 360 & 2400 & 480.64 & 961.3 \\
\hline $20 \%$ & 1920 & 480 & 2400 & 480.64 & 961.3 \\
\hline
\end{tabular}


the materials along to supply geopolymer repair mortar. The impact of manufacturing geopolymer mortar is on its workability and strength. Fly Ash, fine Aggregates were initial mixed along within the dry kind in pan mixer for up to few minutes. Then Normal tap water is added to alkaline solution for more than 2 minutes. After that, the mixture of basic resolution and water is added to dry elements and blend unceasingly for an additional four minutes. Before all these, apply oil to the inside of the moulds and then cast the mixture in mould (Table 1).

\subsection{Fresh Properties}

Flow take a look at was conducted directly once the blending of dry elements consistent with IS-456.

\subsection{Hardened Properties}

During this testing the traditional compressive strength of geopolymer mortar was done supported IS-456. Cubes with dimensions $50 \times 50 \times 50$ millimetre were tested by Compression testing machine. The take a look at was administrated at the ages of three, 7 and 28 days.

\section{Manufacturing of FA Geopolymer Mortar}

The geopolymer mortar made with fly ash was produced for comparison with commercial geopolymer mortar. daylight activity was performed in Apr and should for activity ash geopolymer mortar. Then take a look at conducted on ash repair geopolymer mortar were flow take a look at and compressive strength test. of these tests were conducted consistent with same IS-456. Also, mixing, activity and putting for ash geopolymer mortar is done properly.

\section{Results and Discussion}

This try was created during this analysis and numerous trials were conducted to produce or make geopolymer mortar. Curing of geopolymer mortar is done in two ways as this should be necessary for the research. Compressive strength is conducted to carry out the optimum strength of ash geopolymer mortar. The geopolymermortar has very high strength at earlier time (Table 2).

\subsection{Effect of Extra Water Content}

Due to increase within the water content in ash geopolymer mortar, there's associate degree adverse impact on its compressive strength. the rise of water causes loses binding properties and takes more time for setting to its final stage. Proper compaction cannot be done due to extra water in it. Also, the workability reduces as the flow test fails if the water percent is high.

\subsection{Effect of $\mathrm{NaOH}$ Concentration}

The $\mathrm{NaOH}$ concentration plays a significant role on the compressive strength development of ash geopolymer mortar. thanks to increase of $\mathrm{NaOH}$ content in ash geopolymer mortar, the compressive strength additionally will increase. the method of geopolymerization desires sturdy alkali to activate semiconducting material and metal in ash. By increasing the concentration of $\mathrm{NaOH}$

Table 2. Compressive strength gain (in Mpa) for the following days

\begin{tabular}{|c|c|c|c|c|}
\hline \multicolumn{5}{|c|}{ Compressive Strength } \\
\hline Days & $\mathbf{0 \%}$ & $\mathbf{1 0 \%}$ & $\mathbf{1 5 \%}$ & $\mathbf{2 0 \%}$ \\
\hline 3 & 3.31 & 11.68 & 16.51 & 20.07 \\
\hline 7 & 18.26 & 28.63 & 31.22 & 38.91 \\
\hline 28 & 40.47 & 44.59 & 47.74 & 50.63 \\
\hline
\end{tabular}


resolution, there is increase in formation of aluminosilicate gel at the early stages.

\section{Conclusion}

Local manufactured fly ash was doable to be used for geopolymer mortar. traditional activity is that the effective method for activity for activity ash geopolymer mortar. The curing done under sunlight is free of cost, energy and does not have any bad effect on the environment. High ratio of water and alkali activator does not lead to increase the compressive strength. The correct and optimum compressive strength of ash geopolymer mortar was obtained once the cement replacement is 2 hundredth with ash.

The compressive strength of geopolymer mortar victimisation industrial grade $\mathrm{Na}_{2} \mathrm{SiO}_{3}$ was higher as compare to commercial geopolymer mortar. Geopolymers can provide best replacement with ordinary Portand cement binders. Not just for environmental edges, however, additionally for the economic purpose, reduced emission of $\mathrm{CO}_{2}$, and also in terms of their performances and durability.

\section{References}

1. Wardhonoa A, Lawb DW, Stranob A. Strength of alkali-activated slag/fly ash mortar blends at ambient temperature. Procedia Engineering. 2015; 125:650-6. https:// doi.org/10.1016/j.proeng.2015.11.095.

2. Singh B, Ishwarya G, Gupta M, Bhattacharyya SK. Geopolymer concrete: A review of some recent developments. Construction and Building Materials. 2015; 85:78-90. https://doi.org/10.1016/j.conbuildmat.2015.03.036.

3. Gualtieri ML, Romagnoli M, Pollastri S, Gualtieri AF. Inorganic polymers from laterite using activation with alkaline sodium silicate solution and phosphoric acid: Mechanical and microstructural properties. Cement and Concrete Research. 2015; 67:259-70. https://doi. org/10.1016/j.cemconres.2014.08.010.

4. Zhang HY, Kodur V, Qi SL, Wu B. Characterizing the bond strength of geopolymers at ambient and elevated temperatures. Cement and Concrete Composites. 2015; 58:40-9. https://doi.org/10.1016/j.cemconcomp.2015.01.006.

5. Sanjayan JG, Nazari A, Chen L, Nguyen GH. Physical and mechanical properties of lightweight aerated geopolymer. Construction and Building Materials; 2015. p. 236-44. https://doi.org/10.1016/j.conbuildmat.2015.01.043.

6. Latifa MA, Naganathan S, Razak HA, Mustapha KN. Performance of lime kiln dust as cementitious material. Procedia Engineering. 2015; 125:780-7. https://doi. org/10.1016/j.proeng.2015.11.135.

7. Wiyonoa D, Antonia, Djwantoro Hardjitoa. Improving the durability of pozzolan concrete using alkaline solution and geopolymer coating. Procedia Engineering. 2015; 125:74753. https://doi.org/10.1016/j.proeng.2015.11.121

8. Deba PS, Natha P, Sarker PK. Drying shrinkage of slag blended fly ash geopolymer concrete cured at room temperature. Procedia Engineering. 2015; 125:594-600. https:// doi.org/10.1016/j.proeng.2015.11.066

9. Natha P, Sarkera PK, Rangan VB. Early age properties of low-calcium fly ash geopolymer concrete suitable for ambient curing. Procedia Engineering. 2015; 125:601-7. https:// doi.org/10.1016/j.proeng.2015.11.077.

10. Junaid MT, Kayali O, Khennane A, Black J. A mix design procedure for low calcium alkali activated fly ashbased concretes. Construction and Building Materials. 2015; 79:301-10. https://doi.org/10.1016/j.conbuildmat.2015.01.048.

11. Hossain MM, Karim MR, Hossain MK, Islam MN, Zain MFM. Durability of mortar and concrete containing alkaliactivated binder with pozzolans. Construction and Building Materials. 2015; 93:95-109. https://doi.org/10.1016/j.conbuildmat.2015.05.094. 